\title{
Re: Thoughts on the Current Management of Acute Aluminum Phosphide Toxicity and Proposals for Therapy: An Evidence-based Review
}

Sir,

We read with interest the latest review by Farahani et al. ${ }^{[1]}$ As we have currently proposed a flowchart for treating aluminum phosphide (ALP) poisoning, ${ }^{[2]}$ we think there are some concerns about this article that deserve mention

- Clinical manifestations: Although producing methemoglobinemia is theoretically possible in ALP poisoning none of the cited references confirmed it as a significant byproduct. They used a co-oximeter to confirm methemoglobinemia, while as shown before, this could be a dyshemoglobin falsely positive for methemoglobin by the co-oximeter ${ }^{[3,4]}$

- Gastric decontamination: We think gastric ventilation - by evacuation of phosphine from gastrointestinal (GI) tract - is another possible hypothesis but needs investigation. ${ }^{[5]}$ In addition, although water-soluble compounds such as potassium permanganate can theoretically induce $\mathrm{pH}_{3}$ released within seconds postingestion, they may change metal phosphide to less toxic phosphate components. On the other hand, since they have not used this modality of treatment in their routine practice, one would have expected a lower mortality, which was not the case. The authors chose not to use bicarbonate for gastric decontamination with a similar hypothesis. We all know that phosphine release is facilitated by moisture and stomach acidity. ${ }^{[2]}$ In reality, we cannot dry the GI secretions, but we can reduce the stomach acidity by sodium bicarbonate. Bearing in mind that phosphine starts to be released seconds after GI contact, we may retard its complete release. The authors advised bicarbonate in treating ALP poisoning with $\mathrm{pH}<7,{ }^{[1]}$ another practice that has not decreased their mortality rates. These recommendations are against other reports and are based on unproven hypotheses. ${ }^{[2]}$ While the authors are against using water-soluble material, they simultaneously used bicarbonate and potassium permanganate for gastric decontamination in a recent case report. ${ }^{[1]}$ Activated charcoal can absorb gases including intestinal gas and is traditionally used for treating diarrhea and inflammatory bowel syndrome. It may, therefore, absorb phosphine although combining with water may facilitate phosphine release. This is actually a remedy when phosphine is released in contact with gastric secretions ${ }^{[2]}$ Maitai showed that all three above-mentioned water-soluble materials reduced the mortality rate of rats exposed to metal phosphide with most effective to be bicarbonate and less efficacy with potassium permanganate. ${ }^{[1]}$ More investigations are needed before excluding these remedies from the routine treatment strategy

- Management of severe hypotension/cardiac dysfunction: We recently reported an interventional study to demonstrate the efficacy of glucose/insulin/potassium in treating ALP poisoning and reducing the mortality from $72.7 \%$ to $50 \% \cdot{ }^{[6]}$ Nowadays, this protocol is routinely used in many Iranian centers ${ }^{[2]}$

- Management of severe metabolic acidosis: We agree that metabolic acidosis is a reflection of hypoperfusion, and excessive bicarbonate use may worsen the outcome by reducing tissue $\mathrm{O}_{2}$ delivery. However, there is a direct link between cardiac failure and arrhythmia in ALP poisoning with severe metabolic acidosis. In the study of Jaiswal et al., all 12 patients with electrocardiogram abnormalities survived after full correction of metabolic acidosis and survival rate improved to $55 \%$ among 40 patients. ${ }^{[7]}$ 


\section{Financial support and sponsorship}

Nil.

\section{Conflicts of interest}

There are no conflicts of interest.

Hossein Hassanian-Moghaddam ${ }^{1,2}$, Nasim Zamani ${ }^{1,2}$

${ }^{1}$ Toxicological Research Center, Department of Clinical Toxicology, School of Medicine, Shahid Beheshti University of Medical Sciences, ${ }^{2}$ Excellence Center of Clinical Toxicology, Iranian Ministry of Health and Medical Education, Tehran, Iran

Address for correspondence: Dr. Hossein Hassanian-Moghaddam, Loghman-Hakim Hospital, Kamali Ave, South Karegar, Tehran 13336, Iran. E-mail: hassanian@sbmu.ac.ir

\section{References}

1. Farahani MV, Soroosh D, Marashi SM. Thoughts on the current management of acute aluminum phosphide toxicity and proposals for therapy: An evidence-based review. Indian J Crit Care Med 2016;20:724-30.

2. Hashemi-Domeneh B, Zamani N, Hassanian-Moghaddam H, Rahimi M, Shadnia S, Erfantalab P, et al. A review of aluminium phosphide poisoning and a flowchart to treat it. Arh Hig Rada Toksikol 2016;67:183-93.

3. Mashayekhian $M$, Hassanian-Moghaddam $H$, Rahimi $M$, Zamani N, Aghabiklooei A, Shadnia S. Elevated carboxyhaemoglobin concentrations by pulse CO-Oximetry is associated with severe aluminium phosphide poisoning. Basic Clin Pharmacol Toxicol 2016;119:322-9

4. Zamani N, Hassanian-Moghaddam H. RE: Methemoglobin measurements are underestimated by the Radical 7 CO-oximeter: Experience from a series of moderate to severe propanil poisonings. Clin Toxicol (Phila) 2016:1. DOI: 10.1080/15563650.2016.1263856.

5. Hassanian-Moghaddam H, Shahbazi A. Gastric ventilation: A new approach to metal phosphide fumigant ingestion. Clin Toxicol (Phila) 2012;50:435-7.

6. Hassanian-Moghaddam H, Zamani N. Therapeutic role of hyperinsulinemia/euglycemia in aluminum phosphide poisoning. Medicine (Baltimore) 2016;95:e4349.

7. Jaiswal S, Verma RK, Tewari N. Aluminum phosphide poisoning: Effect of correction of severe metabolic acidosis on patient outcome. Indian J Crit Care Med 2009;13:21-4.

This is an open access article distributed under the terms of the Creative Commons Attribution-NonCommercial-ShareAlike 3.0 License, which allows others to remix, tweak, and build upon the work non-commercially, as long as the author is credited and the new creations are licensed under the identical terms.

\begin{tabular}{|l|l|}
\hline \multicolumn{2}{|c|}{ Access this article online } \\
\hline Quick Response Code: & Website: \\
\hline & www.ijccm.org \\
\hline
\end{tabular}

How to cite this article: Hassanian-Moghaddam H, Zamani N. Re: thoughts on the current management of acute aluminum phosphide toxicity and proposals for therapy: An evidence-based review. Indian J Crit Care Med 2017;21:61-2.

C 2017 Indian Journal of Critical Care Medicine | Published by Wolters Kluwer - Medknow 